\title{
Reflexão social, controle percebido e motivações à adoção: características psicossociais das mães adotivas
}

\author{
Caroline Tozzi Reppold \\ Universidade Federal do Rio Grande do Sul, Universidade do Oeste de Santa Catarina e Centro Universitário Feevale \\ Claudio Simon Hutz \\ Universidade Federal do Rio Grande do Sul
}

\begin{abstract}
Resumo
A literatura mostra que a adoção é associada no imaginário social ao altruísmo e ao hedonismo dos adotantes. O objetivo deste estudo foi investigar algumas características psicossociais de mães adotivas, como as motivações à adoção, o nível de julgamento moral, as crenças de locus de controle e a percepção de apoio social. A amostra foi composta por 20 mães adotivas e 20 mães biológicas. Os dados foram coletados utilizando um questionário com itens psicossociais, o Sociomoral Reflection Objective Measure e a Escala Multidimensional de Locus de Controle de Levenson. Os resultados revelaram que 60\% das participantes relacionaram a adoção a problemas de fertilidade, mas as análises não indicaram diferenças significativas entre o tipo de maternidade e as variáveis investigadas, à exceção do apoio social percebido. Os resultados sugerem novas direções às pesquisas sobre os fatores moderadores da adaptação psicológica das famílias adotivas.
\end{abstract}

Palavras-chave: adoção, julgamento moral, controle percebido

\begin{abstract}
Social reflection, perceived control, and motivation to adopt a child: psychosocial characteristics of adoptive mothers. The literature points out that the social imaginary of adoption is associated with altruism and hedonism of adopters. Thus, the present study aimed to investigate some psychosocial characteristics of adoptive mothers, such as the motivation to adopt, moral judgment, locus of control, and perceived social support. The participants were 20 adoptive and 20 biological mothers. Data were collected using a questionnaire of psychosocial items, the Sociomoral Reflection Objective Measure, and Levenson's Multidimensional Locus of Control Scale. The results indicated that $60 \%$ of participants related adoption to fertility problems. However except for perceived social support, there were no significant differences between the type of maternity and the variables investigated. The results suggest new directions for studies about the moderator factors of psychological adaptation of adoptive families.
\end{abstract}

Key words: adoption, moral judgment, perceived control

A adoção pode ser definida como a criação de um relacionamento afiliativo que envolve aspectos jurídicos, ociais e afetivos que a diferenciam da filiação biológica. Dentre tais distinções, pode-se citar a exposição a um processo avaliativo realizado para fins de habilitação à adoção, a indeterminação temporal da "gestação" adotiva, o desconhecimento da história pregressa do adotado e a excessiva valorização social dos laços consangüíneos (Brodzinsky, Schechter \& Henig, 1993; Brodzinsky, Smith \& Brodzinsky, 1998; Grotevant \& Kohler, 1999; Reppold, 2001). Tais contingências, somadas à diversidade dos resultados encontrados na literatura sobre o ajustamento psíquico dos filhos adoti- vos (Fu I \& Matarazzo, 2001; Miller, Fan, Christensen, Grotevant \& Dulmen, 2000; Sharma, McGue \& Benson, 1998), reforçam o estigma de que a adoção é associada à vulnerabilidade psicológica ou à filantropia dos pais adotantes. Contudo, pouco se sabe até então sobre a extensão na qual o enfrentamento destes fatores relaciona-se a atributos pessoais dos pais e à motivação para a adoção. Neste sentido, a presente pesquisa visa à investigação de alguns aspectos psicossociais da maternidade adotiva, tais como as motivações para a parentalidade, o nível de reflexão social, as crenças de locus de controle e a percepção de apoio social recebido, entre outros. 


\section{Motivações para a parentalidade adotiva}

Os fatores que determinam as motivações para a adoção são um tema bastante polêmico entre os pesquisadores da área, especialmente após a promulgação do artigo 43 do Estatuto da Criança e do Adolescente (13/07/1990), o qual descreve que "a adoção será deferida quando apresentar reais vantagens para o adotando e fundar-se em motivos legítimos" (p. 20). Desde então, membros da comunidade acadêmica e judiciária discutem os critérios referentes à habilitação dos pais adotivos e à legitimidade de suas intenções.

Alguns autores expressam que a investigação dos interesses dos pais ao efetuar uma adoção é um aspecto fundamental, visto que esta variável é um indicador da qualidade da interação entre pais e filhos (Brodzinsky et al., 1998; Tabajaski, Gaiger \& Rodrigues, 1998). Estes pesquisadores afirmam, por exemplo, que as adoções motivadas pela perda recente de um filho ou de um parente próximo implicam potenciais dificuldades de adaptação decorrentes da fragilidade em que os pais se encontram naquele momento. Isto porque o luto a ser elaborado pode ser um obstáculo para a criação de uma rede de apoio que ajude o filho a constituir um autoconceito positivo e a enfrentar as perdas advindas do processo adotivo, tais como o distanciamento da família biológica e da cultura de origem. Neste caso, o propósito reparador da adoção, explicita uma motivação centrada no interesse superior dos adotantes e não propriamente do adotado.

Outro exemplo no qual se observa uma situação em que a criança ou adolescente passa a ser vista como um meio e não como um fim é o tipo de adoção que ocorre em decorrência da crença de que a inclusão de uma criança na família aumentaria a probabilidade de fecundação dos casais com problemas de fertilidade. A partir da pesquisa realizada por Weber (1999), constata-se que esta idéia parece ser bastante difundida na sociedade. Os resultados apresentados no estudo que investigou os estigmas da perfilhação revelam que $44 \%$ dos entrevistados concordam que a adoção pode ter uma função instrumental de facilitar a realização do desejo parental de ter um filho biológico. Ou seja, coadunam com o intento de utilizar uma criança adotiva para diminuir a ansiedade frente às dificuldades de reprodução e aumentar as chances de concepção.

Por outro lado, há pesquisadores que questionam se a investigação das motivações à adoção deva fazer parte do processo de habilitação dos adotantes realizado pelos profissionais do Judiciário (Casellato, 1998; Coimbra, 1999; Weber, 1997). Na percepção destes autores, alguns técnicos subestimam a capacidade de adaptação dos adotivos, contra-indicando a adoção, sem oferecer aos candidatos espaço para reflexão e preparação para mudanças ${ }^{1}$. A fim de avaliar a eficiência do processo de seleção dos adotantes, Weber, Cornélio, Gagno \& Silva (1995) realizaram uma pesquisa que evidenciou não haver correlações significativas entre as motivações para o exercício da parentalidade adotiva e o sucesso da adoção. Este dado é corroborado por Weber (2001) em outro estudo, que concluiu que o fato de a perfilhação ser impulsionada por questões altruístas ou pela infertilidade dos pais não se relaciona a dificuldades educacionais ou de vinculação afetiva do adotado. Em contrapartida, Reppold (2001) demonstra que os adolescentes adotados, incluídos em famílias que convivem com a esterilidade masculina, tendem a perceber seus pais como mais negligentes que os demais, o que pode estar associado a uma confusão cultural que existe entre fecundação e virilidade (Maldonado, 1995). Observa-se que o pai incapaz de gerar filhos congênitos, bem como sua companheira, apresenta maior dificuldade em estabelecer um ambiente familiar que suporte a exploração das questões relativas à adoção e a sustentação de uma auto-imagem positiva. Desta forma, o baixo envolvimento com a criação do filho pode ser entendido como uma estratégia de esquiva frente a questões de identidade pessoal e sexual mal resolvidas, tanto por parte do pai, quanto da mãe, que deve renunciar a sua capacidade reprodutiva ao optar pela adoção.

Frente à disparidade dos dados apresentados, verificase, portanto, que não há consenso entre os profissionais da área sobre a associação entre os fatores que impulsionam os pais a adotar um filho ou sobre a qualidade da relação estabelecida entre estes. Provavelmente, isto ocorra porque a avaliação de um aspecto isolado da adoção (no caso, a motivação parental) é pouco efetiva frente à diversidade de variáveis envolvidas na saúde emocional dos membros de famílias adotivas (Reppold \& Hutz, 2002).

Todavia, deve-se considerar que as motivações expressas pelos pais repercutem na representação que as pessoas têm sobre os adotantes. Em geral, a percepção social sobre o que leva os indivíduos a adotar uma criança ou um adolescente centra-se em dois pólos antagônicos: o altruísmo (comportamento pró-social que visa a atender as necessidades alheias em detrimento de benefícios ou interesses particulares) ou o hedonismo (busca da satisfação dos próprios desejos). Em vista disto, pode-se pensar que haveria uma relação entre as motivações para a parentalidade adotiva e algumas variáveis psicológicas dos pais, como o nível de reflexão social, a crença de atribuição de causalidade e a percepção de apoio social recebido.

Uma pesquisa de campo realizada por Weber (2001) demonstrou que a adoção ainda é associada, no imaginário social, à caridade e à filantropia. Possivelmente isto ocorre porque a representação social da adoção é vinculada, muitas vezes, à prevalência de dificuldades psicológicas, especialmente à maior incidência de problemas de externalização e de déficit de aprendizagem. De fato, nesta direção apontam vários estudos sobre a adaptação dos adotivos, conforme revela a meta-análise realizada por Wierzbicki (1993). Porém, devese considerar que muitas pesquisas que conduzem a esta conclusão apresentam sérias limitações metodológicas, como a utilização de técnicas de amostragem não-probabilísticas e a desconsideração de que as famílias adotivas tendem a ser menos omissas às dificuldades dos filhos, o que a aumenta a representatividade dos adotados nas populações clínicas (Reppold, 2001).

De qualquer forma, frente à crença de que a adoção implica maior risco pessoal e social de desajustamento, observase que muitas pessoas interpretam a inserção das crianças ou 
adolescentes em lares substitutos como um ato de altruísmo e abnegação daqueles que os acolhem. Provavelmente, esta postura reflita a visão assistencialista que fomentou as práticas de proteção infanto-juvenil na Europa, a partir do século XVII, e dois séculos depois no Brasil. A assistência oferecida, então, às crianças abandonadas não se restringia à oferta de cuidados referentes à saúde física destas, pois grande ênfase era dada a sua formação moral e humanitária, especialmente nas instituições asilares de caráter religioso que abrigavam órfãos e desamparados. A diretriz que norteava estas ações era a benevolência cristã, a qual buscava a salvação pessoal através de ações que denotavam, ao mesmo tempo, virtude, fraternidade, compaixão diante da miséria humana e a expectativa de uma submissão agradecida (Marcílio, 1997; Rizzini, 1997).

Apesar das mudanças observadas ao longo dos séculos na perspectiva das políticas de atendimento social, a associação entre caridade e proteção infantil continua a repercutir atualmente junto à cultura da adoção. Isto porque muitos consideram a perfilhação um ato de solidariedade que afasta órfãos e enjeitados dos vícios e infrações por meio da disponibilidade de um ambiente regenerador e da imposição de práticas disciplinares, as quais as crianças não encontrariam nas ruas. Uma enquete realizada por Weber (1999) revela que a maioria dos entrevistados (67\%) acredita que são os valores religiosos, como caridade, pena e amor ao próximo, que levam as pessoas a adotar. Outro estudo confirma a indicação de que a relevância social é considerada o principal motivo para a adoção entre os grupos de diferentes níveis de escolaridade (Gatti, Campos \& Vargas, 1993). De fato, o desejo de promover o bem-estar infantil é descrito por alguns adotantes como uma de suas principais intenções, o que pode ser percebido a partir de respostas como: “a adoção é um caminho para resolver o problema social”, “queríamos colaborar e dar um lar para uma criança” (Weber, 1998, p. 92).

Weber (2001) ressalta que as adoções impulsionadas por razões solidárias, relatadas por 36,7\% de sua amostra, são mais comuns nas famílias de menor poder aquisitivo e naquelas onde já existem filhos biológicos. Em comparação aos pais inférteis, aqueles que adotam por motivações altruístas, em geral, são mais críticos em relação aos filhos, atribuindolhes mais predicados negativos. Já os pais que recorrem à adoção em razão de sua incapacidade reprodutiva tendem a ter uma visão mais positiva de seus filhos e a fazer mais exigências quanto às características da criança/adolescente a ser adotado.

Diversos estudos nacionais e internacionais indicam que a maioria das famílias adotantes busca, na perfilhação, uma forma de suprir seu desejo de parentalidade quando, por problemas orgânicos ou psicológicos, uma gravidez biológica não é viável (Brodzinsky et al., 1993, 1998; Casellato, 1998; Ebrahim, 2001; Grotevant \& Kohler, 1999; Weber, 2001). Portanto, a colocação de uma criança ou adolescente nestas famílias parece vir, prioritariamente, ao encontro do interesse pessoal dos pais em atender a um anseio de ser um cuidador, de perpetuar algumas tradições familiares através do legado a seus filhos, ou de responder à pressão social que sofrem para que tenham filhos.
Dentre as motivações hedonistas, pode-se apontar também aquelas que centram suas intenções em uma relação de submissão, gratidão e reconhecimento a ser estabelecida com o adotado. Nestes casos, a adoção ocorre com o propósito de que o filho adotivo seja capaz de ajudar nos afazeres domésticos, na criação dos irmãos menores ou no cuidado e atendimento às necessidades do adotante no futuro (Brodzinsky et al., 1998; Marcílio, 1997). Novamente, estes dados devem ser compreendidos sob uma perspectiva histórica. Fonseca (1995) relata que, no início do século XX, muitas adoções realizadas por casais eram motivadas pela expectativa dos serviços domésticos que o adotado iria prestar como sinal de retribuição ou respeito (o que os colocava na situação de “criados" da casa, e não como um membro da família de fato) e, principalmente, pela possibilidade de enviar o filho adotado para o serviço militar, poupando, assim, um filho consangüíneo desta obrigação. Observe-se também que a adoção não implicava igualdade de direito entre os filhos. Estes eram tratados na condição de bens, cujos retornos eram esperados a médio e longo prazo. Entretanto, como, na época, a adoção tinha um caráter reversível, muitos pais biológicos reivindicavam novamente a guarda de seus filhos quando estes já se encontravam aptos ao emprego. Conforme se constata, este tipo de interesse pela criação de crianças/adolescentes, até hoje vigente (especialmente nos casos de "adoção informal”, como é conhecida a adoção que ocorre alheia ao ordenamento jurídico e que não garante qualquer direito ao adotado), é, muitas vezes, guiado por uma intenção instrumental e por uma perspectiva individualista e concreta, embora muitos casos de adoção informal possam também decorrer de motivações altruístas.

Seja pela hipótese de maior hedonismo ou de preocupação com o respeito aos direitos e necessidades básicas das crianças colocadas em adoção (proteção, assistência etc.), pode-se pensar que haveria uma diferenciação dos níveis de reflexão social entre famílias adotivas e biológicas. Portanto, o presente estudo também investigou os níveis de julgamento moral apresentados pelas mães adotivas e biológicas.

\section{Julgamento Moral}

A aquisição de valores morais tem sido enfatizada pela Psicologia em vista da estreita relação deste construto com o desenvolvimento de características essenciais à adaptação psicológica, como a empatia, a eqüidade, o altruísmo, a reciprocidade, a afetividade e o bem-estar subjetivo. Desde a década de 60, pesquisadores têm proposto diferentes concepções teóricas sobre a obtenção e evolução da maturidade humana, privilegiando, entre outros, aspectos afetivos, cognitivos ou comportamentais deste complexo fenômeno (Kohlberg, 1982). As principais diretrizes divergem ao abordar a moralidade em termos da maturação cognitiva do indivíduo ou da internalização de valores culturais (Turiel, 1998).

As teorias psicodinâmicas postulam que o processo de internalização dos padrões normativos de socialização implica obediência às regras morais diante da ausência de incentivos ou sanções externas e decorre da identificação com as exigências e interdições parentais, segundo a Psicanálise, ou 
com outros modelos relevantes ao longo da vida, segundo a Psicologia do Ego. Tanto para a Psicanálise quanto para as abordagens comportamentais, as reações punitivas que ocorrem frente à transgressão de padrões culturais são a base dos pressupostos morais (Biaggio, 1999; Kochanska, 1991; Smetana, Schlagman \& Adams, 1993). Para o Behaviorismo, o senso de justiça e as ações morais decorrem da aprendizagem de contingências de reforçamento e punição. Ou seja, do controle exercido pelo ambiente social (Skinner, 1983). Já a Teoria da Aprendizagem Social compreende que a moralidade é fruto da interação entre o meio em que o indivíduo está inserido e suas capacidades cognitivas, o que lhe possibilita autoregular seu comportamento a partir da internalização de regras (Bandura, 1997).

A abordagem Cognitiva-Desenvolvimental aproxima-se do modelo Sócio-Cognitivo de Bandura em sua perspectiva interacionista, embora designe um papel menos significativo à relevância das influências sociais (Kohlberg, 1964; Piaget, 1932/1994). As teorias de Piaget e Kohlberg tratam a questão da moralidade como uma sequiência regular e universal de estágios que se diferenciam pela reorganização qualitativa dos padrões de raciocínio dos indivíduos.

Piaget analisou o desenvolvimento moral considerando o modo como as experiências de vida dos sujeitos influenciavam a formação de julgamentos sobre regras e relacionamentos sociais. Seus estudos revelaram que a moralidade se inicia pela coação de um adulto (heteronomia e realismo moral) e se encaminha para a autonomia, cooperação, reciprocidade e solidariedade. A partir dessas idéias, Kohlberg (1964), um dos principais teóricos da moralidade, lançou seu próprio modelo sobre o desenvolvimento moral. Suas pesquisas endossaram o paralelismo entre a lógica e a moral e reformularam os métodos de estudo nesta área, trazendo importantes contribuições para a compreensão da moral entre jovens e adultos. Além disso, reafirmaram a universalidade cultural dos processos cognitivos e morais ${ }^{2}$.

O modelo de Kohlberg (1964), formulado a partir da noção de um sujeito epistêmico, propõe que a capacidade argumentativa dos indivíduos torna-se gradativamente mais complexa à medida que emergem novas estruturas lógicas. Tais estruturas possibilitam maior articulação do raciocínio e promovem diferentes estágios de consciência moral, que se distinguem pela apreciação de valores básicos, tais como o direito à vida e à liberdade. Assim como Piaget, Kohlberg descreveu essa seqüência como invariante, embora considerasse que nem todos os indivíduos atinjam a maturidade dos níveis mais elevados. A classificação dos estágios é baseada na avaliação do raciocínio utilizado como justificativa de uma ação hipotética diante de um dilema moral (perspectiva deontológica). Portanto, para a determinação do nível de reflexão do indivíduo, a argumentação racional e os motivos alegados pelo indivíduo como parâmetros de sua conduta são mais importantes do que o conteúdo ou a direção de suas respostas.

Kohlberg (1982) distingue três níveis de desenvolvimento moral, sendo cada um destes subdividido em dois estágios. No nível pré-convencional, a moralidade resume-se a um conjunto de normas externas, que são orientadas para a esquiva de punições (estágio um) ou para o prazer hedonista, a satisfação de necessidades individuais e o utilitarismo (estágio dois).

O nível convencional pode ser definido a partir da internalização de normas sociais e morais vigentes. O conformismo ao papel convencional que o distingue pode ser observado pela busca de aprovação social, característica do estágio três, e pelo respeito à autoridade e à manutenção do sistema social, características do estágio quatro.

A moralidade pós-convencional refere-se a princípios éticos universais, tais como o direito à vida, à assistência ou à justiça. A busca de transformação social nesse nível ocorre através de uma interpretação relativista da lei em prol da promoção do bem comum (estágio cinco) ou de princípios individuais de consciência (estágio seis). O nível pós-convencional é característico de uma minoria de adultos (em torno de 5\%), em geral, maior de 25 anos. Em vista deste reduzido percentual, a validade conceitual deste último estágio foi questionada e refutada por Kohlberg durante a construção de sua teoria, voltando a ser defendida pelo autor pouco antes de seu falecimento (Kohlberg, Boyd \& Levine, 1990).

Há várias formas de avaliar o nível de julgamento moral. Além do Moral Judgment Interview, criado pelo próprio Kohlberg, há dois instrumentos objetivos formulados a partir da concepção Kohlbergiana: o Defining Issues Test e o Sociomoral Reflection Objective Measure. Cabe ressaltar que níveis mais elevados de raciocínio moral são esperados quando comparados os escores obtidos em testes objetivos a medidas subjetivas (Koller et al., 1994).

Ao considerar o raciocínio expresso nas diferentes respostas, o sistema de codificação de Kohlberg representa uma média do nível de raciocínio moral apresentado pelo indivíduo com certa freqüência. O modelo de Kohlberg pressupõe que os sujeitos podem manifestar justificativas características de estágios adjacentes, mas suas limitações cognitivas os impedem de utilizar um raciocínio lógico próprio de dois ou mais estágios adiante daquele que lhe é dominante (Koller \& Bernardes, 1997).

Em relação à prevalência do nível de julgamento moral, os resultados de pesquisa têm indicado que o nível convencional é alcançado pela maioria dos adolescentes e adultos de sociedades ocidentais (Biaggio, Vargas, Monteiro, Souza \& Tesche, 1999). Contudo, a revisão apresentada por Koller e Bernardes (1997) revela ser esperado uma menor incidência dos níveis convencional e pós-convencional entre os sujeitos provenientes do meio rural, de sociedades não industriais ou de culturas não ocidentais. No Brasil, Monteiro (2000) avalia que a maioria dos adultos não clínicos se encontra entre os estágios $2 / 3,3$ e 3/4, o que revela uma orientação para a moralidade interpessoal e uma preocupação em manter a confiança e a aprovação social.

Desde a formulação do modelo de Kohlberg (1964), muitos estudos têm procurado associar a moralidade a variáveis psicológicas, traços de personalidade e fatores demográficos (Araújo, 2000; Eisenberg, Carlo, Murphy \& Van Court, 1995; Haidt, Koller \& Dias, 1993; Koller, 1988; Konchaska, 1991; 
Nucci, Camino \& Sapiro, 1996). Dentre os estudos que interessam à presente pesquisa, destacam-se aqueles que apresentam uma correlação positiva entre idade, escolaridade e maturidade de julgamento moral (para revisão, vide Turiel, 1998) e aqueles que evidenciam uma associação significativa entre a crença de locus de controle e o nível de reflexão social do indivíduo (Bachrach, Huesmann \& Peterson, 1977; Murk \& Addleman,1992).

Um estudo sobre julgamento moral e locus de controle, realizado por Biaggio \& Guazelli (1984), é particularmente importante por revelar que a tendência dos indivíduos que atingem o nível pós-convencional à internalidade de locus de controle também ocorre no contexto brasileiro. Tal relação seria explicada pela autoconfiança e boa expectativa de desempenho dos sujeitos capazes de criticar a moral vigente e desejar modificá-la.

\section{Locus de Controle}

Locus de controle é um conceito referente a crenças que os sujeitos estabelecem sobre a fonte de controle dos comportamentos e eventos cotidianos que ocorrem consigo ou no ambiente em que estão inseridos (Rotter, 1966). Enquanto alguns indivíduos acreditam ser responsáveis pelos acontecimentos de sua vida, outros os percebem como controlados por fatores externos, como o destino, a sorte e a influência de outras pessoas ou entidades.

O modelo que descreve as crenças de locus de controle enquadra-se na Teoria de Controle Percebido, que se caracteriza por abordar, de uma maneira geral, as inferências causais atribuídas pelos indivíduos e as suas conseqüências sobre a adaptação psicológica. Em relação aos efeitos que produz sobre o desenvolvimento, observa-se que o domínio, o controle e a compreensão que os sujeitos têm das causas que determinam seus eventos de vida relacionam-se à motivação, ao desempenho de competências e habilidades, aos níveis de saúde emocional (bem-estar, autoconceito, percepção de rede de apoio social e depressão) e às estratégias de ação utilizadas. Ou seja, os indivíduos que atribuem seus sucessos a esforços e atributos pessoais tendem a desenvolver mais afetos positivos e melhores expectativas de desempenho do que aqueles que os atribuem a outras dimensões. Já aqueles que justificam seus fracassos através da inaptidão e falta de capacidade, tendem a sentirem-se culpados, ansiosos, amedrontados, a apresentarem menor rendimento acadêmico e a serem mais ambivalentes diante da necessidade de tomadas de decisões (Eccles, Wigfield \& Schiefele, 1998). A literatura distingue três áreas que são substancialmente afetadas pelo controle percebido: o comportamento, as capacidades cognitivas e as expressões afetivas (Eccles et al., 1998; Silva, 1999).

As investigações que determinam tais associações consideram, além de locus de controle, outros três construtos correlacionados que constituem a base dos estudos sobre controle percebido: a auto-eficácia, o desamparo aprendido e o estilo atribucional. Os autores que trabalham com a noção de causalidade diferem não apenas quanto à direção de suas pesquisas, como também em seus pressupostos teóricos. Uma destas diferenças refere-se às dimensões que envolvem a descrição da causalidade. Enquanto Rotter (1990) afirma que as crenças de locus de controle apresentam duas variações (internalidade e externalidade), definidas em termos de uma perspectiva cognitiva, outros pesquisadores indicam que tais crenças envolvem fenômenos perceptivos (Levenson, 1973) ou motivacionais (Graham, 1994).

A partir dos fundamentos cognitivistas do controle percebido, expostos por Rotter (1966), um modelo teórico de Atribuição de Causalidade foi elaborado por Weiner (1983). Como Rotter, Weiner enfatiza que a interpretação das pessoas sobre os eventos de vida é mais importante para a tomada de decisão do que disposições motivacionais ou os resultados reais do evento em foco. Todavia, em diferencial à proposta de Rotter, Weiner acrescenta duas novas dimensões ao processo atribucional e afirma haver uma tendência individual para um determinado tipo de inferência causal.

As dimensões do modelo de Weiner (1983) referem-se ao locus de causalidade (interno ou externo), à natureza temporal das causas (estável ou instável) e à possibilidade de controle volitivo (controlável ou incontrolável). Entretanto, este autor destaca que, devido à manifestação de mecanismos defensivos, a atribuição de causalidade não é meramente racional e depende também da natureza valorativa dos eventos. Situações positivas tendem a se relacionar a causas internas, e as negativas, às externas (Xenikou, Furnham \& McCarrey, 1997). Nessa perspectiva, Dela Coleta (1982) demonstra que as pessoas que sofreram graves adversidades em sua história de vida (inclusive a incapacitação física) tendem à externalidade.

Ao afirmar a existência de predisposições atribucionais como traços cognitivos, Weiner (1983) enfatiza que o processo de explicações causais envolve uma variável de personalidade, estável no tempo. Portanto, o estilo atribucional (tendência a um tipo de percepção causal) descrito por Weiner e endossado por outros autores (Silva, 1999; Worchel, Cooper \& Goethals, 1990) difere do modelo de Locus de Controle de Rotter (1966), que propõe que cada evento implica uma avaliação situacional específica.

O pressuposto caráter individual do estilo de atribuição de causalidade e as dimensões internalidade e estabilidade que compõem o modelo de Weiner (1983) também são observados na teoria de Desamparo Aprendido concebida por Seligman (1970). Contudo, a abordagem de Seligman inclui a globalidade como uma nova propriedade das causas. Este modelo propõe que os indivíduos que tendem a classificar os eventos aversivos que lhe ocorrem como algo incontrolável, imutável, generalizável a outras situações e determinado por deficiências individuais são mais propensos a desenvolver um quadro de apatia, desalento, pessimismo e depressão (Abramson, Seligman \& Teasdale, 1978). Nesta direção, outras pesquisas também demonstram que a associação entre internalidade e controle relaciona-se a maiores índices de bemestar subjetivo, sendo, portanto, determinante de estilos atribucionais mais saudáveis e adaptativos (Eccles et al., 1998; Findley \& Cooper, 1983; Weiner, 1988). Frente a estes resultados, alguns autores, como Glasgow, Dornbusch, Troyler, 
Steinber e Ritter (1997) categorizam os estilos atribucionais como uma característica de personalidade funcional ou disfuncional. Nesta perspectiva, um padrão funcional estaria vinculado à apresentação de um comportamento exploratório, a um maior repertório de habilidades sociais, à maior autonomia e autoconfiança e à disponibilidade de assumir as conseqüências dos atos praticados. Em contrapartida, um padrão disfuncional seria caracterizado pela dificuldade do indivíduo confrontar-se com seus dolos e, conseqüentemente, pela delegação de responsabilidade a fatores externos, menor engajamento em situações desafiadoras, maior passividade, maior dificuldade em discriminar as contingências ambientais e menor crença de auto-eficácia.

O crescente interesse da literatura em compreender os mecanismos envolvidos na determinação dos estilos atribucionais produziu muitos estudos na área criticando a visão estática deste construto (Collins, 1974; Dell’Aglio \& Hutz, 2002; Welton, Adkins, Ingle \& Dixon, 1996). Segundo estes autores, a avaliação das inferências causais enquanto um traço de personalidade implica um julgamento descontextualizado da situação que a suscitou. Além disso, a criação de uma tipologia sugere uma apreciação valorativa das crenças formuladas pelos indivíduos, que, igualmente, desconsidera a assertividade do comportamento emitido e as possibilidades viáveis de ação perante a magnitude da adversidade que se impôs. Neste sentido, a teoria de Locus de Controle descrita por Levenson (1973), a qual considera a dimensão perceptiva do conceito, parece ser um dos eixos mais adequados da abordagem de Controle Percebido, visto que avalia as crenças de controle em termos situacionais, e não a partir de uma tendência estável.

É preciso ressaltar, todavia, que historicamente a constituição do modelo pressuposto de Locus de Controle, em parte, contribuiu para a análise descontextualizada das inferências causais. Tal reducionismo teve origem no uso de escalas de avaliação supostamente unifatoriais, como a escala criada por Rotter (1966) no início de sua pesquisa (Tamayo, 1989). A Escala de Locus de Controle Interno-Externo, proposta por Rotter, foi um dos primeiros testes psicométricos elaborados nessa área e o mais difundido. Originalmente, o instrumento não foi construído como um inventário de avaliação geral, mas como uma medida de expectativa referente a várias áreas. Contudo, análises fatoriais demonstraram sua unidimensionalidade, tornando esse teste num instrumento de avaliação global, cujo resultado distribui-se entre duas polaridades: a internalidade e a externalidade.

Diversos trabalhos subseqüentes ao estudo de Rotter (1966) criticaram a imprecisão do termo externalidade e foram mais adiante para elucidar as especificidades e o significado psicológico que o conceito implica (Collins, 1974; Connell, 1985; Dela Coleta, 1987; Presson, Clark \& Benassi, 1997; Welton et al., 1996). Dentre estes, destaca-se o estudo de Levenson (1973).

Ao considerar que a externalidade não é um indicativo de características depreciativas do sujeito, uma vez que a percepção de controle externo pode corresponder à realidade de uma situação específica, Levenson (1973) desenvolveu uma escala multidimensional de locus de controle. Esse instrumento é baseado teoricamente em Rotter (1966), mas distingue-se pela forma de apresentação (tipo Lickert), pela distinção pessoal-ideológica realizada e pela separação das dimensões de controle externo. Ao supor que as pessoas que acreditam no poder de outros sobre si diferem daquelas que percebem os acontecimentos como imprevisíveis, Levenson equacionou o construto de externalidade de Rotter em duas dimensões independentes: a casualidade e o poder de terceiros. Portanto, o inventário de Levenson considera como fatores analisáveis a internalidade, o acaso e a influência de outros poderosos.

No Brasil, a Escala Multidimensional de Locus de Controle de Levenson foi adaptada por Dela Coleta (1987). Os resultados de Dela Coleta evidenciaram maiores escores na escala internalidade, cujo escore médio foi 28,4 ( $d p=4,6)$. Os fatores acaso e outros poderosos apresentaram valores médios aproximados entre si (acaso: $M=19,3$ e $d p=5$,6; outros poderosos: $M=18,3$ e $d p=4,9$ ), tal qual ocorre em amostras norte-americanas (Levenson, 1981, citado por Dela Coleta, 1987). A percepção de controle pelo acaso relaciona-se às maiores diferenças entre os subgrupos avaliados pela autora. Observa-se, ainda, que a idade e o grau de escolaridade dos participantes relacionaram-se negativamente à crença de controle em outros poderosos. Outro estudo nacional, realizado por Pasquali, Alves e Pereira (1998), também encontrou evidências de que a internalidade correlaciona-se positivamente com o nível de escolaridade. Em vista destes resultados, o presente trabalho propôs-se também a analisar a relação existente entre as crenças de locus de controle e as demais variáveis consideradas.

\section{Método}

\section{Participantes}

Participaram desse estudo 40 mulheres, 20 mães adotivas e 20 mães biológicas. Ambos grupos foram emparelhados em relação à idade, escolaridade, situação conjugal e número de filhos. A faixa etária dos grupos variou entre 30 e 71 anos e a média de idade foi 42,2 anos $(d p=9,25)$. O grau de escolaridade mais freqüente da amostra foi o nível superior (60\%), seguido pelo ensino médio (25\%) e fundamental (15\%). Ressalte-se que as categorias de escolaridade foram agrupadas de modo abrangente, a fim de garantir maior representatividade dos diferentes níveis de instrução.

A maioria das participantes era casada (55\%). As mulheres solteiras, viúvas e separadas ou divorciadas distribuíramse igualmente no restante da amostra. Em geral, as participantes eram mães de um único filho (60\%). Na amostra adotiva, 25\% das mulheres já haviam se submetido a processos de inseminação artificial.

Quanto aos motivos da adoção, 60\% das adotantes relacionaram-na ao fato de não poder ter filhos biológicos. Os demais motivos citados foram o desejo de maternidade de mulheres solteiras (10\%), a importância social (10\%), a perda de um filho (5\%) e o acolhimento de um parente (5\%), entre outros. 


\section{Instrumentos}

Os dados sócio-demográficos das participantes foram coletados através de um questionário contendo informações referentes a características pessoais, familiares e sócio-econômicas, bem como à percepção do apoio social recebido após o nascimento ou adoção do filho. No grupo adotivo, a ficha descritiva incluía, ainda, alguns itens relativos ao histórico da adoção realizada. Os demais instrumentos utilizados neste estudo foram a Escala Multidimensional de Locus de Controle de Levenson (Dela Coleta, 1987) e a adaptação brasileira do Sociomoral Reflection Objective Measure (Biaggio \& Barreto, 1991).

O Sociomoral Reflection Objective Measure (SROM) é um instrumento unidimensional de investigação do nível de maturidade moral dos indivíduos. O inventário, elaborado originalmente por Gibbs, Arnold e Burkhart (1984), é composto por dezesseis itens baseados em dois dilemas morais hipotéticos. Cada item é constituído por alternativas que expressam respostas típicas dos diferentes estágios de desenvolvimento moral propostos por Kohlberg. Em cada questão, existe ainda uma opção de "resposta alienada”, sem significado semântico, cuja finalidade é excluir da amostra os indivíduos descomprometidos com o estudo ou cognitivamente limitados, visto que três ou mais respostas deste tipo invalidam o protocolo.

As respostas dos participantes indicam sua avaliação sobre a conduta das personagens das histórias e os argumentos que norteiam seu julgamento. A soma dos escores obtidos pode variar de 100 a 500 pontos. Isto ocorre devido à desconsideração do estágio 6 (princípios universais de consciência).

Quanto às características psicométricas do instrumento, os índices de fidedignidade e consistência interna obtidos na versão original foram satisfatórios (fidedignidade do tipo temporal =0,82; Alpha de Crombach =0,84 e 0,77 em duas amostras). A validade de construto do instrumento foi avaliada através de correlações com as variáveis idade, escolaridade e nível de inteligência (QI), indicando bons resultados. Também a adaptação do instrumento para população brasileira, realizada por Biaggio \& Barreto (1991), demonstrou que o inventário apresenta propriedades psicométricas adequadas à sua aplicação. A correlação entre as respostas apresentadas ao SROM e a outra medida de avaliação de julgamento moral (as Situações de Julgamento Moral de Kohlberg) revelou um resultado igual a 0,45.

A Escala Multidimensional de Locus de Controle de Levenson, adaptada por Dela Coleta (1987), é um instrumento objetivo de auto-relato que visa à investigação das explicações causais formuladas pelos indivíduos para justificar a ocorrência dos eventos descritos. Trata-se de uma medida multidimensional, composta por 24 itens, referentes às crenças de internalidade (I), acaso (C) e outros poderosos (P). As respostas referentes ao teste ocorrem através de uma escala tipo Likert de cinco pontos, na qual os participantes devem indicar o grau de concordância com a questão apresentada. Os resultados de cada subescala estendem-se em um interva- lo de oito a quarenta pontos. Quanto maior o escore obtido, maior é a crença do participante de que o fator correspondente àquela subescala é o responsável pelo controle de seus eventos de vida. Entretanto, baixos escores em uma subescala não são indicativos de que o participante atribua controle a outras fontes. Expressam apenas descrença naquela fonte controladora.

A adaptação do instrumento para a população brasileira, realizada por Dela Coleta (1987), evidenciou que a escala apresenta características psicométricas satisfatórias. A validade fatorial do instrumento adaptado foi também corroborada pelo trabalho de Tamayo (1989) que demonstrou que a consistência interna das subescalas varia entre 0,57 e 0,69.

\section{Procedimentos}

A seleção das participantes ocorreu em dois momentos, para viabilizar o emparelhamento de variáveis demográficas em ambos grupos. Inicialmente, três mães adotivas foram contatadas a partir do cadastro de um grupo de adotantes, informadas sobre os objetivos do estudo e convidadas a participar da pesquisa e a indicar outras mães adotivas não pertencentes a grupos de apoio à adoção.

Após a realização do levantamento demográfico da amostra adotante, coletaram-se os dados entre as mães biológicas correspondentes, selecionadas em escolas. A aplicação dos instrumentos realizou-se na residência da participante, após combinação prévia. O questionário e as escalas foram aplicados de forma individual, sendo lidos e respondidos pela própria participante. $\mathrm{O}$ anonimato e a confidencialidade das informações foram garantidos. Incluiu-se na amostra apenas as mães que preencheram de forma completa todos instrumentos e que entregaram um consentimento informado da sua participação na pesquisa. Em ambos os grupos, a ordem de aplicação dos testes foi aleatória para cada participante.

Foi disponibilizada aos grupos a oportunidade de uma devolução individual da avaliação realizada. Para tanto, solicitou-se que as interessadas registrassem um dado pessoal de sua escolha que possibilitasse a identificação dos instrumentos correspondentes.

\section{Resultados}

Não foram encontradas diferenças significativas entre o nível de julgamento moral de mães biológicas e mães adotivas $(t=0,44$, g.l. $=38, p<0,66)$. Da mesma forma, os escores obtidos nas subescalas de locus de controle não apresentaram diferenças entre os grupos em nenhum dos fatores avaliados (internalidade: $t=0,81$, g.l. $=38, p<0,94$; acaso: $t=1,10$, g.l. $=38, p<0,28$; outros poderosos: $t=0,88$, g.l. $=38, p<$ $0,94)$. Os resultados referentes às médias obtidas pelos grupos nas escalas de julgamento moral e locus de controle são apresentados na Tabela 1 .

$\mathrm{Na}$ amostra total, foi encontrada uma correlação positiva e significativa entre o nível de julgamento moral e a crença de internalidade de locus de controle $(r=0,50, p<0,01)$. Outra correlação significativa ocorreu entre os fatores acaso e outros poderosos $(r=0,60, p<0,01)$. 
Tabela 1

Médias e desvios-padrão de Julgamento Moral e Locus de Controle, conforme o Tipo de Maternidade $(\mathrm{n}=20)$.

\begin{tabular}{lcc}
\hline \multicolumn{1}{c}{ Escalas e tipos de maternidade } & $M$ & $d p$ \\
& & \\
Escore de Julgamento Moral & 385,0 & 42,76 \\
$\quad$ Adotiva & 377,9 & 57,67 \\
$\quad$ Biológica & & \\
Locus de Controle - Fator Acaso & 16,1 & 5,44 \\
$\quad$ Adotiva & 18,3 & 7,35 \\
Biológica & & \\
Locus de Controle - Fator Outros Poderosos & 17,0 & 5,12 \\
$\quad$ Adotiva & 16,8 & 5,67 \\
Biológica & & \\
Locus de Controle - Fator Internalidade & 30,0 & 4,51 \\
Adotiva & 29,8 & 6,99 \\
$\quad$ Biológica & & \\
\hline
\end{tabular}

Na amostra de mães adotivas, verificou-se que os motivos alegados para a adoção não diferenciam as mães quanto a seus níveis de reflexão social ou controle percebido. Neste grupo, devido ao reduzido tamanho da amostra adotiva, optou-se por um teste não paramétrico (Mann-Whitney) para fins desta avaliação. Entre as mulheres que se submeteram à fertilização artificial prévia, analisou-se também se elas apresentavam níveis de julgamento moral e de locus de controle distintos das que não realizaram tal procedimento. Os resultados não revelaram diferenças significativas entre maturidade de julgamento moral e locus de controle nos grupos com e sem experiência de fertilização artificial. $\mathrm{O}$ fator que mais se aproximou de um índice significativo $(p<0,07)$ é o que se caracteriza pela atribuição dos eventos de vida à influência de outros poderosos.

Quanto à relação existente entre as variáveis sóciodemográficas e os índices referentes à raciocínio moral e às crenças de locus de controle, encontrou-se uma diferença significativa entre os grupos de diferentes níveis de escolaridade quanto aos escores de julgamento moral $[F(2,37)=$ 13,63, $p<0,01]$. Conforme se observa na Tabela 2, o Teste de Tukey indicou que as diferenças ocorrem entre os subgrupos $1^{\underline{0}}$ e $3^{\underline{0}}$ grau $(p<0,01)$ e $2^{\underline{0}}$ e $3^{\underline{0}}$ grau $(p<0,05)$.

Os dados apresentados na Tabela 2 indicam ainda que 0 nível de escolaridade não implicou, nesta amostra, diferenças significativas entre os fatores acaso $[F(2,37)=2,73, p<0,08]$ e internalidade $[F(2,37)=1,30, p<0,29]$. A única diferença encontrada refere-se à crença em outros poderosos $[F(2,37)$ $=4,42, p<0,02]$. Quanto maior o grau de instrução do indivíduo, menor é sua tendência a explicar os eventos de sua vida a partir do controle externo de outros poderosos.

A análise das diferenças entre o estado civil das participantes e os escores obtidos nas escalas utilizadas indicou a rejeição da hipótese de independência no que se refere ao

Tabela 2

Média e desvio-padrão dos escores de Julgamento Moral e Locus de Controle por Nível de Instrução.

\begin{tabular}{|c|c|c|c|c|c|c|c|c|}
\hline \multirow{3}{*}{ Nível de Instrução } & \multirow{2}{*}{\multicolumn{2}{|c|}{ Julgamento moral }} & \multicolumn{6}{|c|}{ Locus de controle } \\
\hline & & & \multicolumn{2}{|c|}{ Internalidade } & \multicolumn{2}{|c|}{ Acaso } & \multicolumn{2}{|c|}{ Outros poderosos } \\
\hline & $M$ & $d p$ & $M$ & $d p$ & $M$ & $d p$ & $M$ & $d p$ \\
\hline $\begin{array}{l}\text { Ensino Fundamental } \\
\qquad\left(1^{\circ} \text { Grau }\right)\end{array}$ & $328,3^{\mathrm{a}}$ & 25,17 & $26,8^{\mathrm{a}}$ & 6,91 & $22,1^{\mathrm{a}}$ & 9,06 & $21,8^{\mathrm{a}}$ & 5,04 \\
\hline $\begin{array}{l}\text { Ensino Médio } \\
\left.\text { ( } 2^{-} \text {Grau }\right)\end{array}$ & $351,6^{\mathrm{a}}$ & 44,18 & $29,3^{\mathrm{a}}$ & 6,67 & $18,0^{\mathrm{a}}$ & 7,12 & $16,7^{\mathrm{ab}}$ & 5,38 \\
\hline $\begin{array}{l}\text { Ensino Superior } \\
\qquad\left(3^{-} \text {Grau }\right)\end{array}$ & $407,2^{b}$ & 39,53 & $30,9^{\mathrm{a}}$ & 5,06 & $15,6^{\mathrm{a}}$ & 4,94 & $14,3^{\mathrm{b}}$ & 4,70 \\
\hline
\end{tabular}

Nota. As médias dispostas na mesma coluna que apresentam indicadores distintos diferem significativamente entre si pelo Teste de Tukey $(p<0,05)$. 
julgamento moral $[F(3,36)=3,48, p<0,05]$. Uma das diferenças significativas estabelecidas ocorreu entre as mulheres casadas e as separadas ou divorciadas $(p<0,05)$. Também quanto ao nível de internalidade do locus de controle encontrou-se uma diferença significativa relativa à situação conjugal $[F(3,36)=2,99, p<0,05]$. Os resultados são apresentados na Tabela 3.

No que se refere à descrição de apoio percebido (qualquer forma de assistência, conforto ou informação provida) dos grupos sociais a que pertence a participante, observouse que a percepção da amostra adotiva quanto ao apoio recebido quando da colocação da criança na família difere significativamente do grupo das mães biológicas $\left(\chi^{2}=8,43\right.$, g.l. $=2$, $p<0,01)$. Já em relação ao apoio do marido ou companheiro e dos parentes próximos não houve diferenças significantes (marido ou companheiro: $\chi^{2}=0,66$, g.l. $=2, p<0,71$; parentes: $\chi^{2}=1,45$, g.l. $\left.=2, p<0,48\right)$. Sobre a percepção do estigma da adoção, na amostra adotante, $70 \%$ das mães relataram já ter vivenciado episódios de discriminação em razão da situação adotiva de seus filhos.

\section{Discussão}

Os resultados não revelaram diferenças significativas entre os níveis de julgamento moral e locus de controle entre mães adotivas e biológicas. Por um lado, esses dados apontam para a necessidade de desmistificar as afirmações do senso comum que indicam uma expectativa de maior filantropia ou maior hedonismo entre os adotantes. Por outro, faz-se necessário considerar que $40 \%$ da amostra alegou outras motivações para a adoção que não a infertilidade, mas não possuía filhos biológicos. Portanto, é possível que as causas mencionadas sejam uma resposta "politicamente correta", ou mesmo uma esquiva frente à frustração da impossibilidade de gerar filhos congênitos. De qualquer forma, esses achados repercutem sobre a compreensão da dinâmica das famílias adotivas e dos mecanismos que determinam as motivações à parentalidade adotiva.
Embora alguns estudos relacionem a adoção ao altruísmo (Ebrahim, 2001; Weber, 2001), afirmando que esta é uma característica comum tanto às famílias que já possuem filhos, quanto àquelas que realizam adoções atípicas (tardias, interraciais, ou de portadores de necessidades especiais), é preciso enfatizar que a maioria das famílias adotantes apresenta como principal motivação à adoção a infertilidade. Além disso, impõe alguns requisitos sobre os atributos pessoais da criança ou adolescente a ser perfilhado que demonstram que a aceitação não é incondicional, nem regida pela lógica de alcançar o interesse do outro em detrimentos aos seus próprios. O fato de as crianças negras, maiores de dois anos de idade ou portadoras de necessidades especiais esperarem por uma família substituta por um tempo substancialmente maior do que as crianças brancas e recém-nascidas (Chaves, 2000) revela que a adoção, ainda hoje, é interpretada por algumas pessoas como uma forma de viabilizar aos pais, inférteis ou não, filhos saudáveis, que pareçam, em termos de fisionomia, muito próximos de seus adotantes.

Ainda em relação à discriminação associada à adoção, os resultados evidenciaram a grande freqüência das situações de preconceito a que as famílias adotivas são expostas, o que pode, inclusive, justificar as dificuldades de adaptação dos adotados (Brodzinsky et al., 1998; Reppold \& Hutz, 2002), ou o menor apoio social percebido pelas mães adotantes. Visto que o apoio recebido é um importante fator protetivo à adaptação psicológica, os dados apresentados deveriam ser considerados pelos profissionais de saúde envolvidos nos processos de adoção, a fim de trabalhar com as famílias a constituição de redes de apoio que contemplem suas necessidades. Uma vez que a assistência e responsividade social de terceiros podem repercutir diretamente sobre a saúde emocional das crianças recém colocadas em novos lares substitutos (através do cuidado que disponibiliza) e também de forma indireta, por meio do aumento do bem-estar e autoconfiança da mãe, a promoção de redes de apoio emocionais e instrumentais é uma forma de oportunizar contingências para um melhor ajustamento das famílias adotivas.

Tabela 3

Média e desvio-padrão dos escores de Julgamento Moral e Locus de Controle por Situação Conjugal.

\begin{tabular}{|c|c|c|c|c|c|c|c|c|}
\hline \multirow{3}{*}{ Situação Conjugal } & \multirow{2}{*}{\multicolumn{2}{|c|}{ Julgamento Moral }} & \multicolumn{6}{|c|}{ Locus de Controle } \\
\hline & & & \multicolumn{2}{|c|}{ Internalidade } & \multicolumn{2}{|c|}{ Acaso } & \multicolumn{2}{|c|}{ Outros Poderosos } \\
\hline & $M$ & $d p$ & $M$ & $d p$ & $M$ & $d p$ & $M$ & $d p$ \\
\hline Solteira & $406,5^{\mathrm{ab}}$ & 25,85 & $34,0^{\mathrm{a}}$ & 3,41 & $15,5^{\mathrm{a}}$ & 6,25 & $16,6^{\mathrm{a}}$ & 5,96 \\
\hline Casada & $368,1^{\mathrm{ab}}$ & 51,15 & $28,9^{\mathrm{ab}}$ & 6,05 & $16,4^{\mathrm{a}}$ & 6,45 & $17,4^{\mathrm{a}}$ & 5,54 \\
\hline Separada/Divorciada & $426,0^{b}$ & 46,77 & $33,1^{\mathrm{ab}}$ & 3,25 & $20,0^{\mathrm{a}}$ & 6,60 & $14,1^{\mathrm{a}}$ & 3,31 \\
\hline Viúva & $360,6^{\mathrm{a}}$ & 37,63 & $26,3^{b}$ & 5,89 & $20,2^{\mathrm{a}}$ & 6,49 & $18,1^{\mathrm{a}}$ & 5,85 \\
\hline
\end{tabular}

Nota. As médias dispostas na mesma coluna que apresentam indicadores distintos diferem significativamente entre si pelo Teste de Tukey $(p<0,05)$. 
No que refere às demais medidas investigadas, observou-se que os escores de locus de controle aproximam-se dos resultados encontrados em outra amostra brasileira (Dela Coleta, 1987). O mesmo ocorreu em relação ao nível de raciocínio moral. Enquanto os resultados apresentados por Monteiro (2000) variaram entre os estágios 2/3 e 3/4, a média estabelecida neste estudo caracteriza a amostra no subestágio 3/4. Estes dados, que indicam uma orientação para o nível convencional (intermediária entre o estágio da afetividade e da manutenção das leis), provavelmente reflitam uma característica da cultura brasileira: a valorização das relações interpessoais. Esta idéia é endossada por Da Matta (citado por Koller et al., 1994), que sugere que, em nossa sociedade, a resolução de conflitos preconiza, essencialmente, as relações estabelecidas entre os sujeitos, em detrimento aos direitos individuais.

Outro dado interessante encontrado neste estudo foi a diferença significativa obtida entre mulheres casadas e separadas ou divorciadas a propósito da maturidade de julgamento moral e da internalidade de locus de controle. A partir destes achados, pode-se pensar que talvez a situação de separação seja propulsora do desenvolvimento de autoconfiança e independência, ou mesmo conseqüência da autonomia destas mulheres. Um estudo comparativo sobre o ajustamento psicológico e o estado civil de norte-americanas demonstra que as mulheres que apresentam melhores índices de adaptação psicológica, entre estes locus de controle, são as que têm menos conflitos em desempenhar seus papéis de mãe, esposa e trabalhadora (Tholman, 1995).

No que tange à distinção do nível de julgamento moral, é possível pensar que as mulheres separadas conseguiram romper a busca de aprovação social, para a qual a autoconfiança pode ter sido fator essencial. Ressalte-se que a manutenção das boas relações no casamento, característica do estágio três, não deve ser confundida com passividade e submissão, uma vez que a predominância deste estágio ocorre também entre o sexo masculino (Biaggio, 1988).

As análises mostraram ainda uma correlação entre as subescalas acaso e outros poderosos, ambas relativas à crença de controle em fatores externos ao indivíduo. Como este achado contradiz a ortogonalidade dos fatores que compõem a escala de Levenson, o presente estudo suscita novamente as discussões sobre as dimensões consideradas quanto à busca de explicações causais para os diversos eventos e comportamentos experienciados.

A propósito da tendência à crença de controle por outros poderosos, encontrada na amostra com experiência malsucedida de fertilização artificial, uma hipótese que poderia justificá-la é a situação de vulnerabilidade em que as mulheres se colocam frente ao conhecimento técnico e à manipulação de seu corpo. Este resultado pode ser comparado ao estudo de Dela Coleta (1982), que demonstra uma tendência à externalidade pelas vítimas de infortúnio.

A expectativa de controle por outros poderosos relacionou-se, ainda, de forma negativa, com o grau de instrução das participantes. Pode-se considerar que isto esteja ligado à associação que se estabelece no Brasil e em outros países em desenvolvimento entre o nível de escolaridade e a classe so- cial dos indivíduos, os quais assumem direções antagônicas. Todavia, cabe ressaltar que a subordinação econômica não deveria ser sinônimo de menor autonomia psicológica, visto que este é um construto situacional que deve ser analisado em diferentes dimensões (família, trabalho, atividades acadêmicas etc.).

Uma diferença significativa foi obtida entre o grau de instrução das participantes e seu nível de julgamento moral. Pode-se cogitar que o ambiente acadêmico oportunize acesso a discussões que envolvem dilemas morais, de modo a desenvolver a maturidade da reflexão social dos graduandos. Nesta direção, muitos estudos indicam a eficácia dos programas de educação moral (Biaggio et al., 1999; Camino, 1998; Dias, 1999). Por outro lado, as diferenças culturais apontadas na pesquisa podem fomentar as discussões sobre a existência do pluralismo moral. Sob esta perspectiva, Shweder (1990) sugere que é possível distinguir pelo menos duas variantes da ética: a ética da comunidade e a ética da autonomia. Enquanto a ética da comunidade estaria relacionada ao nível convencional de Kohlberg (caracterizado pela coletividade, obediência à autoridade e adequação à expectativa social), a ética da autonomia estaria mais próxima do nível pós-convencional (marcado pela auto-regulação e livre arbítrio). Os estudos que seguem este modelo de moralidade postulam que os indivíduos pertencentes a culturas menos providas economicamente tendem a ser mais sensíveis à ética da comunidade. Ou seja, apresentam mais respeito aos superiores e às normas vigentes e maior engajamento em empreendimentos coletivos, o que os classificaria, segundo os padrões avaliativos de Kohlberg, entre os estágios três e quatro. Outra possibilidade não excludente de interpretação das diferenças nos escores de julgamento moral determinadas pelo grau de instrução é que o melhor desempenho das participantes com maior nível de escolaridade deva-se à melhor compreensão dos itens que compõem o instrumento.

Conforme esperado, ocorreu uma correlação positiva entre a internalidade de locus de controle e a maturidade do nível de julgamento moral. Portanto, pode-se afirmar que, quanto maior a maturidade da reflexão social do indivíduo, maior sua tendência de supor a si próprio como controlador dos fatos que ocorrem em sua vida. Em vista das relações estabelecidas na literatura entre internalidade, motivação e bem-estar (Eccles et al., 1998; Findley \& Cooper, 1983; Glasgow et al., 1997), é provável que a reflexão social se vincule também à expectativa de desempenho, ao desenvolvimento de competência e a outras medidas de saúde emocional, como afetividade e autoconceito.

Os resultados deste trabalho exploratório e suas implicações requerem a realização de outros estudos que o corroborem utilizando amostras maiores e situadas em outros contextos. Apesar de suas limitações, os achados apresentados lançam novas direções às pesquisas subseqüentes relacionadas a uma área ainda incipiente no Brasil: os fatores moderadores da adaptação psicológica das famílias adotivas.

\section{Referências}

Abramson, L. Y., Seligman, M. E. P., \& Teasdale, J. D. (1978). Learned helplessness in humans: critique and reformulation. Journal of Abnormal Psychology, 87, 49-74. 
Araújo, V. A. (2000). Cognição, afetividade e moralidade. Educação e Pesquisa, 26, 137-153.

Bachrach, R., Huesmann, L. R., \& Peterson, R. A. (1977). Relation between locus of control and development of moral judgment. Child Development, 48, 1340-1352.

Bandura, A. (1997). Self-efficacy: the exercise of control. Nova York: W. H. Freeman.

Biaggio, A. M. B. (1988). Desenvolvimento moral: vinte anos de pesquisa no Brasil. Psicologia: Reflexão e Crítica, 2, 60-69.

Biaggio, A. M. B. (1999). Universalismo versus relativismo no julgamento moral. Psicologia: Reflexão e Crítica, 12, 5-19.

Biaggio, A. M. B., \& Barreto, M. S. L. (1991). Adaptação brasileira de uma medida objetiva de julgamento moral. Arquivos Brasileiros de Psicologia, 43, 107-119.

Biaggio, A. M. B., \& Guazelli, E. F. (1984). Relação entre julgamento moral e internalidade de locus de controle. Arquivos Brasileiros de Psicologia, 36, 63-73.

Biaggio, A. M., Vargas, G. A., Monteiro, J. K., Souza, L. K., \& Tesche, S. L. (1999). Promoção de atitudes ambientais favoráveis através de debates de dilemas ecológicos. Estudos de Psicologia, 4, 221-239.

Brodzinsky, D. M., Schechter, M. D., \& Henig, R. M. (1993). Being adopted: the lifelong search of self. Nova York: Anchor Books.

Brodzinsky, D. M., Smith, D. W., \& Brodzinsky, A. B. (1998). Children's adjustment to adoption: developmental and clinical issues. Thousand Oaks: Sage.

Camino, C. (1998). Educação moral: doutrinação ou debate? In M. L. S. Moura, J. Correa \& A. Spinillo (Orgs.), Pesquisas brasileiras em Psicologia do Desenvolvimento (pp. 111-139). Rio de Janeiro: UERJ.

Casellato, G. (1998). Motivos relacionados ao luto que levam um casal à adoção: uma possibilidade psicoprofilática. Dissertação de Mestrado nãopublicada, Curso de Pós-Graduação em Psicologia, Pontifícia Universidade Católica de São Paulo. São Paulo.

Chaves, V. (2000). O perfil das crianças colocadas em adoção no Juizado da Infância e Juventude de Porto Alegre no ano de 1999. Manuscrito nãopublicado, Curso de Pós-Graduação em Psicologia do Desenvolvimento, Universidade Federal do Rio Grande do Sul. Porto Alegre.

Coimbra, J. C. (1999). Pais e filhos adotivos: aspectos psicológicos entre o ideal e o real. Uma Família para uma Criança, 17, 1-3.

Collins, B. (1974). Four components of the Rotter Internal-External Scale: belief in a difficult world, a just world, a predictable world, and a political, responsive world. Journal of Personality and Social Psychology, 29, 381-391.

Connell, J. P. (1985). A new multidimensional measure of children's perception of control. Child Development, 56, 1018-1041.

Dela Coleta, J. A. (1982). Atribuição de causalidade: teoria e pesquisa. Rio de Janeiro: Fundação Getúlio Vargas.

Dela Coleta, M. F. (1987). Escala Multidimensional de Locus de Controle de Levenson. Arquivos Brasileiros de Psicologia, 39, 79-97.

Dell'Aglio, D. D., \& Hutz, C. S. (2002). Estratégias de coping e estilo atribucional de crianças em eventos estressantes. Estudos de Psicologia, 7, 5-13.

Dias, A. A. (1999). Educação moral para a autonomia. Psicologia: Reflexão e Crítica, 12, 459-478.

Ebrahim, S. G. (2001). Adoção tardia: altruísmo, maturidade e estabilidade emocional. Psicologia: Reflexão e Crítica, 14, 73-80.

Eccles, J. S., Wigfield, A., \& Schiefele, U. (1998). Motivation to succeed. In W. Damon (Org. Série) \& N. Eisenberg (Org. Vol.), Handbook of child psychology, Vol. 3. Social, emotional, and personality development (5 $5^{\mathrm{a}}$ ed., pp. 237- 309). Nova York: John Wiley \& Sons.

Eisenberg, N., Carlo, G., Murphy, B., \& Van Court, N. (1995). Prosocial development in late adolescence: a longitudinal study. Child Development, 66, 1179-1197.

Estatuto da Criança e do Adolescente. (1990). Lei Federal no 8069, de 13/07/ 1990. Porto Alegre: CORAG.

Findley, M., \& Cooper, H. (1983). Locus of control and academic achievement: a literature review. Journal of Personality and Social Psychology, 44, 419-427.
Fonseca, C. (1995). Caminhos da adoção. São Paulo: Cortez.

Fu I, L. \& Matarazzo, E. (2001). Prevalência de adoção intra e extrafamiliar em amostras clínicas e não-clínicas de crianças e adolescentes. Revista Brasileira de Psiquiatria, 23, 24-27.

Gatti, A. L., Campos, D. C., \& Vargas, M. M. (1993). Estudo exploratório sobre opiniões e motivações acerca da adoção. Estudos de Psicologia (PUCCAMP), 10, 63-80.

Gibbs, J. C., Arnold, K. D., \& Burkhart, J. E. (1984). Sex differences in the expression of moral judgment. Child Development, 55, 1040-1043.

Glasgow, K. L., Dornbusch, S. M., Troyer, L., Steiberg, L., \& Ritter, P. L. (1997). Parenting styles, adolescent's attributions, and educational outcomes in nine heterogeneous high schools. Child Development, 68, 507-529.

Graham, S. (1994). Motivation in African Americans. Review of Educational Research, 64, 55-117.

Grotevant, H. D., \& Kohler, J. K. (1999). Adoptive families. In M. E. Lamb (Org.), Parenting and child development in "nontraditional" families (pp. 161-190). Hillsdale, New Jersey: Lawrence Erlbaum.

Haidt, J., Koller, S., \& Dias, M. (1993). Affect, culture, and morality, or is it wrong to eat your dog? Journal of Personality and Social Psychology, 65, 613-628.

Kochanska, G. (1991). Socialization and temperament in the development of guilt and conscience. Child Development, 62, 325-347.

Kohlberg, L. (1964). Development of moral character and moral ideology. In M. L. Hoffman \& L. W. Hoffman (Orgs.), Review of child development research (vol. 1, pp. 383-431). Nova York: Russell Sage.

Kohlberg, L. (1982). The philosophy of moral development: moral stages and the idea of justice. São Francisco: Harper \& Row.

Kohlberg, L., Boyd, D. R., \& Levine, C. (1990). The return of stage 6: its principle and moral point of view. In T. E. Wren (Org.), The moral domain: essays in the ongoing discussion between philosophy and social sciences (pp. 151-181).Cambridge: Massachusetts Institute of Technology.

Koller, S. H. (1988). Diferenças no nível de julgamento moral entre menores institucionalizados infratores e não-infratores. Estudos de Psicologia (PUCCAMP), 6, 127-134.

Koller, S. H., \& Bernardes, N. M. G. (1997). Desenvolvimento moral pró-social: semelhanças e diferenças entre os modelos de Eisenberg e Kohlberg. Estudos de Psicologia, 2, 223-262.

Koller, S. H., Biaggio, A. M. B., Lopes, R. S., Neto, J. R., Camino, C., Dias, M. G., \& Costa, A. E. (1994). Uma investigação sobre instrumentos de medida de maturidade de julgamento moral em uso no Brasil. Psicologia: Reflexão e Crítica, 7, 5-14.

Levenson, H. (1973). Multidimensional locus of control in psychiatric patients. Journal of Consulting and Clinical Psychology, 41, 397-404.

Maldonado, M. T. (1995). Os caminhos do coração: pais e filhos adotivos. São Paulo: Saraiva.

Marcílio, M. L. (1997). A roda de expostos e a criança abandonada na história do Brasil: 1726-1950. In M. C. Freitas (Org.), História social da infância no Brasil (pp. 51-76). São Paulo: Cortez.

Miller, B. C., Fan, X., Christensen, M., Grotevant, H. D., \& Dulmen, M. (2000). Comparison of adopted and nonadopted adolescents in a large, nationally representative sample. Child Development, 71, 1458-1473.

Monteiro, J. K. (2000). Julgamento moral, culpa e depressão. Tese de Doutorado não-publicada, Curso de Pós-Graduação em Psicologia do Desenvolvimento, Universidade Federal do Rio Grande do Sul. Porto Alegre.

Murk, D. A., \& Addleman, J. A. (1992). Relations among moral reasoning, locus of control and demographic variables among college students. Psychological Reports, 70, 467-476.

Nucci, L. (2000). Psicologia moral e educação: para além das crianças "boazinhas”. Educação e Pesquisa, 26, 71-89.

Nucci, L., Camino, C., \& Sapiro, C. (1996). Social class effects on Northeastern Brazilian children's concepts of areas choices and social regulation. Child Development, 67, 1223-1242. 
Pasquali, L., Alves, A. R., \& Pereira, M. A. M. (1998). Escala de Locus de Controle ELCO/TELEBRÁS. Psicologia: Reflexão e Crítica, 11, 363-378.

Piaget, J. (1994). O juízo moral na criança. São Paulo: Summus. (Original publicado em 1932).

Presson, P. K., Clark, S. C., \& Benassi, V. A. (1997). The Levenson’s Locus of Control Scales: confirmatory factor analyses and evaluation. Social Behavior and Personality, 25, 93-104.

Reppold, C. T. (2001). Estilo parental percebido e adaptação psicológica de adolescentes adotados. Dissertação de Mestrado não-publicada, Curso de Pós-Graduação em Psicologia do Desenvolvimento, Universidade Federal do Rio Grande do Sul. Porto Alegre.

Reppold, C. T, \& Hutz, C. S. (2002). Adoção: fatores de risco e proteção à adaptação psicológica. In C. S. Hutz (Org.), Situações de risco e vulnerabilidade na infância e na adolescência: aspectos teóricos e estratégias de intervenção (pp. 89-130). São Paulo: Casa do Psicólogo.

Rizzini, I. (1997). O século perdido: raízes históricas das políticas públicas para a infância no Brasil. Rio de Janeiro: USU.

Rotter, J. B. (1966). Generalized expectancies for internal versus external control of reinforcement. Psychological Monographs, 80, 1-28.

Rotter, J. B. (1990). Internal versus external control of reinforcement: a case history of a variable. American Psychologist, 45, 489-493.

Seligman, M. (1970). Desamparo: sobre depressão, desenvolvimento e morte. São Paulo: HUCITEC.

Sharma, A. R., McGue, M. K., \& Benson, P. L. (1998). The psychological adjustment of United States adopted adolescents and their nonadopted siblings. Child Development, 69, 791-802.

Shweder, R. A. (1990). In defense of moral realism: reply to Gabennesch. Child Development, 61, 2060-2067.

Silva, D. F. M. (1999). Estilo atribucional em adolescentes infratores e nãoinfratores. Dissertação de Mestrado não-publicada, Curso de Pós-Graduação em Psicologia do Desenvolvimento, Universidade Federal do Rio Grande do Sul. Porto Alegre.

Skinner, B. F. (1983). O mito da liberdade. São Paulo: Summus.
Smetana, J. G., Schlagman, N., \& Adams, P. W. (1993). Preschool children’s judgment about hypothetical and actual transgressions. Child Development, 64, 202-214.

Tabajaski, B., Gaiger, M., \& Rodrigues, R. (1998). O trabalho do psicólogo no Juizado da Infância e Juventude de Porto Alegre/RS. Aletheia, 7, 9-18.

Tamayo, A. (1989). Validade fatorial da Escala Levenson de Locus de Controle. Psicologia: Teoria e Pesquisa, 5, 111-122.

Tholman, S. P. (1995). Psychosocial correlates of women's health in middle adulthood. Issues in Mental Health Nursing, 16, 285-314.

Turiel, E. (1998). The development of morality. In W. Damon (Org. Série) \& N. Eisenberg (Org. Vol.), Handbook of child psychology, Vol. 3. Social, emotional, and personality development (5 $5^{\underline{a}}$ ed., pp. 863- 932). Nova York: John Wiley \& Sons.

Weber, L. N. D. (1997). Critérios de seleção de pais adotivos: em discussão. Interação, 1, 123-137.

Weber, L. N. D. (1998). Laços de ternura: pesquisas e histórias de adoção. Curitiba: Santa Mônica.

Weber, L. N. D. (1999). Aspectos psicológicos da adoção. Curitiba: Juruá.

Weber, L. N. D. (2001). Pais e filhos por adoção no Brasil: características, expectativas e sentimentos. Curitiba: Juruá.

Weber, L. N. D., Cornélio, S. A., Gagno, A. P., \& Silva, M. L. (1995). Filhos adotivos: amores ou dissabores? Revista de Ciências Humanas, 4, 119-164.

Weiner, B. (1983). Some methodological pitfalls in attributional researches. Journal of Educational Psychology, 75, 530-543.

Weiner, B. (1988). Attribution theory in education. Revista Portuguesa de Educação, 1, 21-25.

Welton, G. L., Adkins, A. G., Ingle, S. L., \& Dixon, W. A. (1996). God control: the fourth dimension. Journal of Psychology and Theology, 24, 13-25.

Wierzbicki, M. (1993). Psychological adjustment of adoptees: a meta-analysis. Journal of Clinical Child Psychology, 22, 447-456.

Worchel, S., Cooper, J., \& Goethals, G. R. (1990). Understanding social psychology. Pacific Grove: Brooks/Cole.

Xenikou, A., Furnham, A., \& McCarrey, M. (1997). Attributional styles for negative events: a proposition for a more reliable and valid measure of attributional style. British Journal of Psychology, 88, 53-69.

\section{Notas}

1 Contudo, deve-se ressaltar que um candidato avaliado como inapto para a adoção em um determinado momento pode ingressar posteriormente com um novo processo de habilitação junto ao Juizado da Infância e Juventude.

2 Ressalte-se a diferença existente entre a universalidade cultural dos processos cognitivos e morais e a unicidade transcultural das convenções sociais. Se valores morais como a integridade e o respeito à vida parecem ser atemporais, convenções sociais variam conforme as normas estabelecidas em determinado tempo e espaço. Neste sentido, Nucci (2000) afirma que a moralidade pode ser definida a partir de concepções subjacentes do indivíduo sobre a garantia de bem-estar e tratamento justo a seus pares, ao passo que as convenções se referem a padrões de conduta estabelecidos por um determinado grupo social, a fim de promover a melhor organização desse.

Caroline Tozzi Reppold, doutoranda do Programa de Pós-graduação em Psicologia do Desenvolvimento pela Universidade Federal do Rio Grande do Sul, é professora da Universidade do Oeste de Santa Catarina e do Centro Universitário Feevale.

Claudio Simon Hutz, doutor em Psicologia pela University of Iowa/EUA, é professor titular da Universidade Federal do Rio Grande do Sul - UFRGS.

Endereço para correspondência: Instituto de Psicologia, UFRGS, Ramiro Barcelos 2600, Porto Alegre, RS, 90035-003. Fone: (51)3316-5076 Fax: (51)3330-4797 E-mail: hutzc@ufrgs.br 